\title{
COORDINATED CHARGING/DISCHARGING OF ELECTRIC VEHICLES IN CHARGING STATIONS INTEGRATED WITH PHOTOVOLTAICS POWER SYSTEM
}

\author{
Eslam A. Zenhom* and Walid A. Omran \\ Electrical Power and Machine Department, Faculty of Engineering, Ain Shams University, \\ Cairo, Egypt. \\ *Corresponding Author Email: eslam.3laa@eng.asu.edu.eg
}

\begin{abstract}
:
The use of electric vehicles is rapidly increasing worldwide due to their environmental benefits. These vehicles operate in the grid-to-vehicle mode when they charge from the grid and sometimes in the vehicle-to-grid mode when they discharge their energy. Thus, electric vehicles can assist charging stations to minimize their operation costs by allowing the charging station to use them as distributed storage. The environmental and economic benefits of electric vehicles can be considerably increased if the charging station is powered by renewable energy sources. This paper addresses charging and discharging schedules of electric vehicles in a charging station integrated with a photovoltaic system. The day-ahead scheduling is optimized to minimize the daily operation cost of the charging station using the whale optimization algorithm which simulates the hunting behavior of humpback whales. The results show that by implementing the proposed charging/discharging approach, the total operating cost of the charging station is decreased as compared to uncoordinated charging.
\end{abstract}

\section{KEYWORDS: Electric Vehicle, Scheduling, Charging Station, Operation Cost, Day-ahead.}

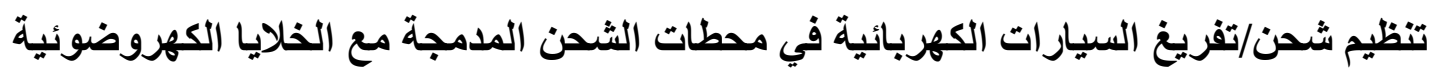

إسلام علاء الدين زينهم* و وليد عاطف عمران

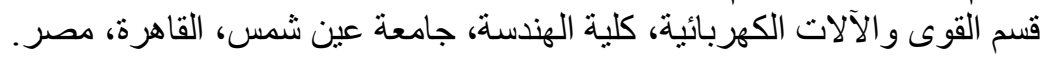

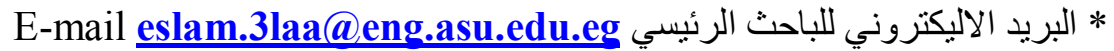

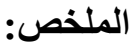

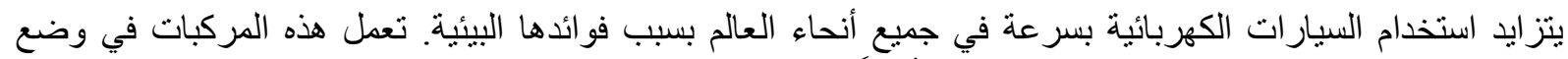

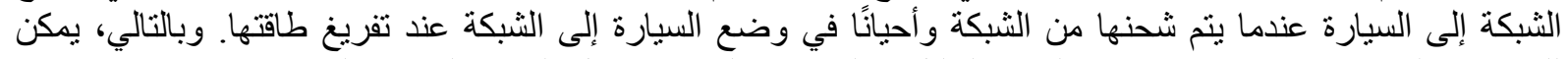

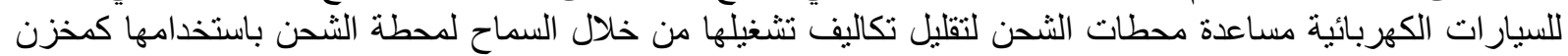

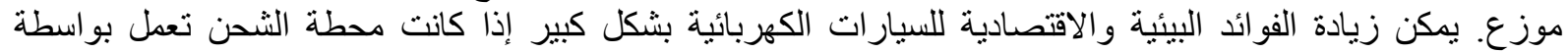

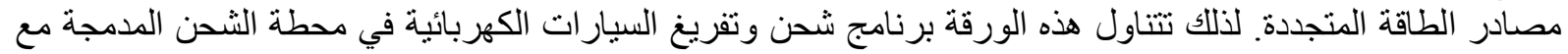

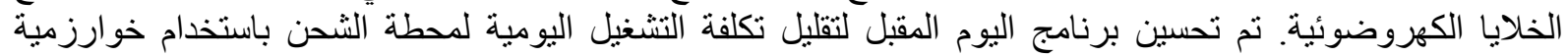

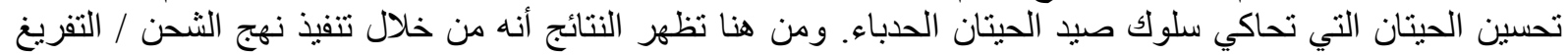

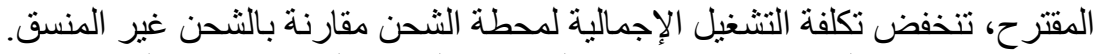
الكلمات المفتاحية: السيارات الكهربائية، الجدولة، محطة الثحن، تكلفة التشغيل، اليوم المقبل. 


\section{NOMENCLATURE}

$e_{m 2}(t) \quad$ Energy of $n^{\text {th }} \mathrm{EV}$ at time slot $t$.

$e_{n, c}(t) \quad$ Charging energy of $n^{\text {th }} \mathrm{EV}$ at time slot $t$.

$e_{n, d}(t)$ Discharging energy of $n^{\text {th }} \mathrm{EV}$ at time slot $t$.

$e_{n a}^{\max } \quad$ Battery capacity of $n^{\text {th }} \mathrm{EV}$.

$J \quad$ Maximum number of iterations.

$j \quad$ Index for number of iterations.

$N \quad$ Total number of EVs in the charging station.

$n \quad$ Index for each $\mathrm{EV}$.

$P_{f}^{\text {out }}(t)$ The power supplied from the grid at time slot $t$.

$P_{f:}^{i n}(t) \quad$ The power back to the grid at time slot $t$.

$P_{e}(t) \quad$ Power supplied from/to the grid at time slot $t$.

$P_{w v}(t) \quad$ The generated PV power at time slot $t$.

$P_{\text {sv,max }} \quad$ PV maximum power.

$P_{n, e}(t) \quad$ The charging power of $n^{\text {th }} \mathrm{EV}$ at time slot $t$.

$p_{n, d}(t) \quad$ The discharging power of $n^{\text {th }} \mathrm{EV}$ at time slot $t$.

$P_{n}(t) \quad$ Charging/discharging power of $n^{\text {th }} \mathrm{EV}$ at time slot $t$.

$p_{s}(t) \quad$ Unit cost of charging EV at time slot $t$.

$p_{r}(t) \quad$ Unit bonus of discharging EV at time slot $t$.

$P_{c h}^{\max } \quad$ Capacity of the charging station.

$P_{r}^{\max } \quad$ Maximum charging power of the charger.

$\operatorname{SoC}_{n}(t)$ State of charge of the battery of $n^{\text {th }}$ EV at time slot $t$.

$S o C_{n \text { max }}$ Maximum state of charge of $n^{\text {th }} \mathrm{EV}$.

SoC $C_{n \text { min }}$ Minimum state of charge of $n^{\text {th }} \mathrm{EV}$.

$T \quad$ Total number of time slots.

$t \quad$ Index for time slot.

$\Delta t \quad$ Duration of time slot.

$t_{n, a} \quad$ Arrival time of $n^{\text {th }} \mathrm{EV}$.

$t_{n, d} \quad$ Departure time of $n^{\text {th }} \mathrm{EV}$.

$\alpha \quad$ A predefined parameter to determine $\sigma_{i, n}(t)$.

$\beta \quad$ A predefined parameter to determine $p_{r}(t)$.

$\gamma \quad$ A predefined parameter to determine $p_{r i}(t)$.

$\sigma_{\text {sm }}(t)$ Unit cost of the energy supplied by the grid at time slot $t$.

$\sigma_{i n}(t) \quad$ Unit cost of the selling energy to the grid at time slot $t$.

$\eta \quad$ EV Battery efficiency.

\section{INTRODUCTION}

With the increasing concerns about the greenhouse gas emissions, recent data show that electricity and transportation sectors share approximately $50 \%$ of the overall global greenhouse gas emissions [1]. The use of electric vehicles (EVs) in the transportation sector is considered a promising solution that can save energy and mitigate greenhouse gas emissions. Nevertheless, the electricity utilized to charge EVs is mostly generated from conventional power plants fueled by fossil fuel. Thus, a significant amount of $\mathrm{CO} 2$ will still be produced due to EVs but moving from the transportation sector to the electricity sector. To solve this problem, integration of renewable energy sources can extremely reduce the emissions [2].

The global sales of EVs is expected to reach approximately 23 million vehicles by 2030 [3]. This rapid increase in the penetration level of EVs may lead to some negative impacts on the electric network in case uncoordinated charging of EVs. Some of these negative impacts include additional power losses, voltage deviation and increased transformer loading [4][5]. 
In general, there are two types of interaction between an EV and the grid, namely, grid-tovehicle $(\mathrm{G} 2 \mathrm{~V})$ and vehicle-to-grid (V2G). In the G2V mode, the power flow is unidirectional where EVs are charged from the electric network. On the other hand, in the V2G mode, the power flow is bidirectional where EVs can be charged from the grid or discharged to the grid [6]. A charging station consists of chargers which can achieve these interactions between an EV and the grid. To alleviate the adverse effects of EVs charging on the electric network, coordinated charging of EVs was investigated in several studies in the literature. For example, in [7], coordinated charging of EVs was proposed to improve voltage profile using GAMS. The study in [8] proposed smart charging using particle swarm optimization for smoothing the system load curve. In [9], optimal charging schedules of EVs under electricity market was proposed to reduce charging cost using dynamic programming but the study was researched on one EV only which is not suitable for charging stations.

The environmental benefits of EVs can be maximized when they are charged from renewable energy sources. Several studies addressed this approach where they considered the integration of photovoltaic (PV) systems with charging stations. In [10], charging scheduling of EVs in a parking lot that has PV panels was proposed to minimize the operating cost using a mixed integer linear programming. In [11], coordinated EV charging scheduling for commercial charging stations using renewable energy sources (PV and wind systems) was presented to maximize the use of renewable energy sources. However, these studies considered the G2V mode only.

The V2G mode of EVs charging has recently attracted the attention of several researchers as it can provide ancillary services to the electric network [12]. For example, in [13], the interaction between EVs and electric network through the V2G option was proposed to lower the peak demand periods and reduce the consumer bill. The study in [14] proposed optimal charging and discharging scheduling of PEVs using mixed discrete programming to flatten the total demand curve while maintaining EV users' requirements. However, these studies didn't consider the integration of renewable energy with the charging station.

The aforementioned researches did not address the charging/discharging of EVs considering renewable energy source. So, in this paper, the charging/discharging scheduling problem for coordinating EVs in a charging station integrated with roof-top PV panels is addressed. The EVs owners are encouraged to contribute in the charging/discharging program by adding a participation bonus. The proposed scheduling approach aims to minimize the operating cost of the charging station using the whale optimization algorithm (WOA) while utilizing the G2V/V2G modes. The remainder of this paper is organized as follows: In the second section, the proposed charging/discharging strategy is presented. In the third section, the scheduling problem is formulated as a linear optimization problem. The WOA used to solve the problem is presented in the fourth section, while in the fifth section, the case studies are presented. Finally, our conclusion is presented in the sixth section.

\section{PROPOSED CHARGING/DISCHARGING STRATEGY}

The system under study is shown in Fig. 1 where it is assumed to consist of a single charging station with $N$ connected EVs. The charging station has level 2 chargers which are characterized by 208 or 240-volt single phase AC, 40 Amp circuit [15]. The charging station is equipped with roof-top PV panels similar to the public charging station made by Honda Japan [16]. The PV panels are connected to the DC-bus of the chargers through a DC/DC converter. The charging sta tion is connected to the grid through a bi-directional inverter which allows the charging station to buy energy from the electric network or sell its surplus energy. The operation of the charging station is administered by the station operator who can collect the information of EVs that will participate in the charging/discharging program. This information include arrival times, departure times and initial state of charges. This information can be obtained by using historical data or by allowing EVs owners to input the data a day ahead before arriving to the charging station. The operator also collects the 
electricity price from the utility and the forecasted data of PV generation. Then, the operator coordinates the charging/discharging schedules of EVs via controlling the chargers in order to minimize the operation cost of the charging station as well as satisfying the EVs requirements.

The duration of the total scheduling time is assumed to be 24 hours which is uniformly divided into $T$ time slots each with duration of $t$ minutes. The charging station operator can make use of the electricity price variations to minimize the operation cost by selecting appropriate time slots to purchase the energy from the electric network and sell the excessive energy to the electric network according to the time-of-use (TOU) pricing which is the electricity price varies according to the time of day, higher prices are charged during the peak demand hours and lower prices during off-peak demand hours.

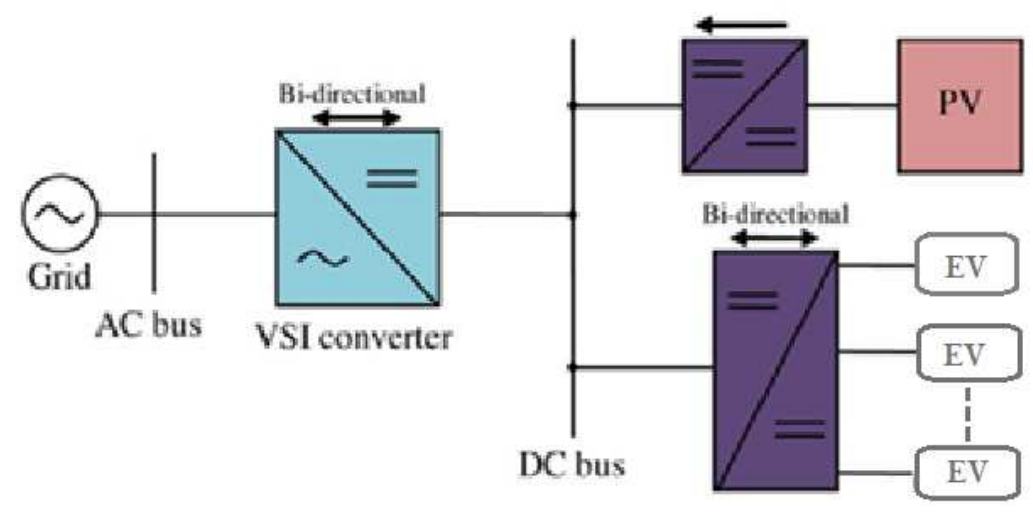

Fig. 1. Structure of The Proposed System

\section{PROBLEM FORMULATION}

\subsection{Objective Function}

Min Cost $=\sum_{t}\left(c_{G}^{\text {out }}(t)+\sum_{n=1}^{N} c_{n, d}(t)-\sum_{n=1}^{N} C_{n, e}(t)-C_{G}^{i n}(t)\right\}$

$C_{f}^{\text {out }}(t)=\sigma_{m s}(t) \cdot P_{f}^{\text {out }}(t) . \Delta t$

$C_{n, d}(t)=p_{d}(t) \cdot P_{n, d}(t) \cdot \Delta t$

$C_{n c}(t)=p_{0}(t) \cdot P_{n c}(t) \cdot \Delta t$

$C_{f}^{i n}(t)=\sigma_{i n}(t) \cdot P_{f}^{i n}(t) \cdot \Delta t$

At time slot $t$, the objective function involves cost of energy drawn from the upstream grid $\left(C_{\varepsilon}^{\text {out }}(t)\right)$, cost of discharging energy of $N$ EVs $\left(\sum_{n=1}^{N} C_{n, d}(t)\right)$, cost of charging energy of $N$ EVs $\left(\sum_{n=1}^{N} C_{n, c}(t)\right)$, and cost of selling energy to the upstream grid $\left(C_{\ell}^{i n}(t)\right)$.

\subsection{Constraints}

A number of constraints should be satisfied in order to ensure that the proposed strategy can be applied in a real environment. In the following, we briefly explain these constraints. 
- Power Balance Constraints

At time slot $t$, the power supplied by the grid, the generated PV power, and the discharging power from EVs should be equal to the power injected to the grid and the power charged to the EVs as follow:

$$
P_{G}^{\text {ond }}(t)+P_{p V}(t)+\Sigma_{n} P_{n, d}(t)=\Sigma_{n} P_{n, \sigma}(t)+P_{G}^{i n}(t)
$$

- Grid Constraints

At time slot $t$, the total power provided from/to the upstream grid $P_{f}(t)$ must not exceed the capacity of the charging station $P_{c h}^{m a x}$.

$$
\begin{aligned}
& P_{f}(t)=P_{f}^{q^{u} t}(t)-P_{f}^{i n}(t) \\
& -P_{c h}^{\max } \leq P_{G}(t) \leq P_{c h}^{\max }
\end{aligned}
$$

- PV Constraints

At time slot $t$, the PV output power must not exceed the PV system maximum power $P_{\text {pvimax }}$.

$$
0 \leq P_{p v}(t) \leq P_{p v \max }
$$

- EV Constraints

- At time slot $t$, the connected EVs can be charged or discharged. The charging/discharging power of each connected EV must not exceed the maximum charging/discharging power of the chargers. It should be noted that the charging and discharging of the same EV is not allowed at the same time slot.

$$
\begin{aligned}
& P_{n}(t)=P_{n, d}(t)-P_{n d}(t) \\
& -P_{c}^{\max } \leq P_{n}(t) \leq P_{c}^{\max }, t_{n, a} \leq t \leq t_{n, d}
\end{aligned}
$$

- The SoC of each $n^{\text {th }}$ connected EV at time slot $t$ is updated by considering the SoC of this $\mathrm{EV}$ at previous time slot $(t-1)$, the energy provided to the EV if it is charged, and the energy injected from the EV if it is discharged as follow:

$$
\begin{aligned}
& e_{n, c}(t)=P_{n, \sigma}(t) \cdot \Delta t \\
& e_{n, d}(t)=P_{n, d}(t) \cdot \Delta t \\
& \forall t_{n, a}<t \leq t_{n, d}, \operatorname{SoC}_{n}(t) \cdot e_{n}^{\text {max }}=\operatorname{SoC}_{n}(t-1) \cdot e_{n}^{\text {max }}+\eta e_{n, c}(t)-e_{n, d}(t)
\end{aligned}
$$

- At time slot $t$, the SoC of each $n^{\text {th }}$ connected EV is limited by an upper limit $\operatorname{SoC} C_{n m a x}$ and a lower limit $S_{0} C_{n, m i n}$ to obviate overcharging and thorough discharging such that

$\operatorname{SoC}_{n, m i n} \leq \operatorname{SoC}_{n}(t) \leq S o C_{n, m a x}$

- The SoC of each $n^{\text {th }}$ connected EV when it leaves the charging station at time $t_{n, d}$ must not exceed the EV battery capacity and must be greater than or equal to $80 \%$ of battery capacity to guarantee leaving with appropriate SoC. 
$e_{n}(t)=P_{n}(t) \cdot \Delta t$

$e_{n}\left(t_{n, a}\right)=S_{0} C_{n}^{t_{n a}} \cdot e_{n}^{\max }$

$0.8 e_{n}^{\max } \leq e_{n}\left(t_{n a}\right)+\Sigma_{t_{n-n}+1}^{t_{n d}}\left(e_{n}(t)\right) \leq e_{n}^{\max }$

\section{WHALE OPTIMIZATION ALGORITHM}

The whale optimization algorithm (WOA) is a meta-heuristic optimization technique based on simulating the humpback whale hunting behaviour [17]. Whales are one of the intelligent creatures who have cells in their brains called spindle cells similar to those of the human cells. These cells are responsible for feeling, judgment, and social behaviors in human. The humpback whales have large number of these cells so they can communicate, learn, think, and become emotional as a human, but with a lower level of smartness. The hunting mechanism of these whales is called bubble-net attacking method where the humpback whales hunt the prey close to the surface. They first search for the prey, then encircle it and create bubbles in a spiral shape around it as shown in Fig. 2. This prevents the prey from escaping and forces it to go towards the surface. Finally, the whales swim up toward the surface and hunt the prey. The flow chart representing the WOA is shown in Fig. 3.

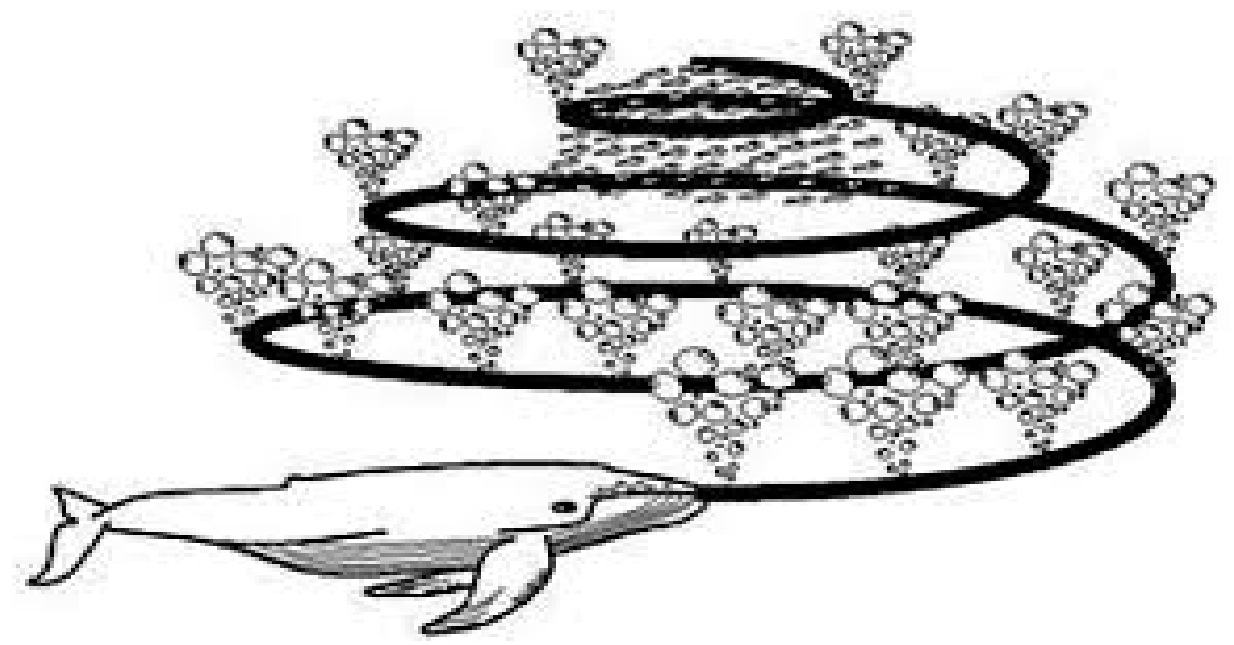

Fig. 2. Bubble-Net Attacking Behavior of Humpback Whale 


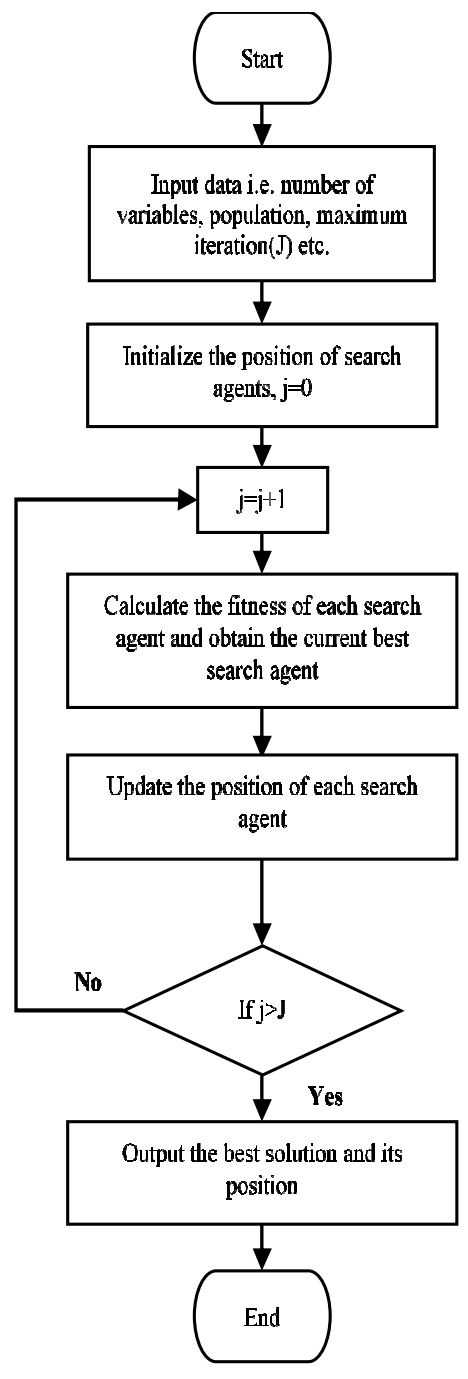

Fig. 3. The Flowchart of WOA

\section{SIMULATIONS AND RESULTS}

In this section, a public charging station with level 2 charging mode (i.e. $6.6 \mathrm{~kW}$ ) is assumed to have 20 chargers and powered by $45 \mathrm{~kW}$ roof-top PV panels with output power profile shown in Fig. 4. Also, it is assumed that there are 40 EVs that need to use the charging station in a period of $24 \mathrm{~h}$ according to the forecasted arrival times, departures times, and state of charges. The EVs are assumed to be equipped with a $36-\mathrm{kWh}$ battery that is $90 \%$ efficient. In addition, it is assumed that all EVs charging in this station are participants in the discharging program. At each time slot $t$, the number of EVs connected to the charging station is limited by the capacity of the station (20 chargers). Thus, when an EV arrives to the station and all the chargers are occupied, the EV will leave. Based on this scenario, there are $32 \mathrm{EVs}$ out of 40 EVs will be plugged into the charging station in a period of $24 \mathrm{~h}$. The day ahead scheduling time is divided into $T=48$ time slots, and each slot has a duration of $t=30$ minutes. The minimum SoC for the $n^{\text {th }} \mathrm{EV}$, SoC $\mathrm{C}_{n, m i n}$, at any time slot $t$ during charging/discharging process is assumed to be greater than or equal $20 \%$. Whereas, the maximum SoC, $S o C_{n, m a x}$, is assumed to be lower than or equal to $100 \%$. The electricity price of power supplied from the grid, $\sigma_{m, t}(t)$, is chosen according to the TOU price as illustrated in Table 1. These values are obtained according to actual TOU price performed during the summer weekdays in Ontario [18]. The electricity price of power supplied to the grid, $\sigma_{i \text { in }}(t)$, 
is assumed to be $\sigma_{\text {sos }}(t)-a$. For each $\mathrm{EV}, p_{n}(t)$ and $p_{\mu}(t)$ are chosen as $p_{n}(t)=\sigma_{m s+}(t)+\beta$ and $p_{n}(t)=p_{n}(t) \times \gamma$ respectively. In our study, we have chosen $\alpha=0.02, \beta=0.03$ and $\gamma=0.75$.

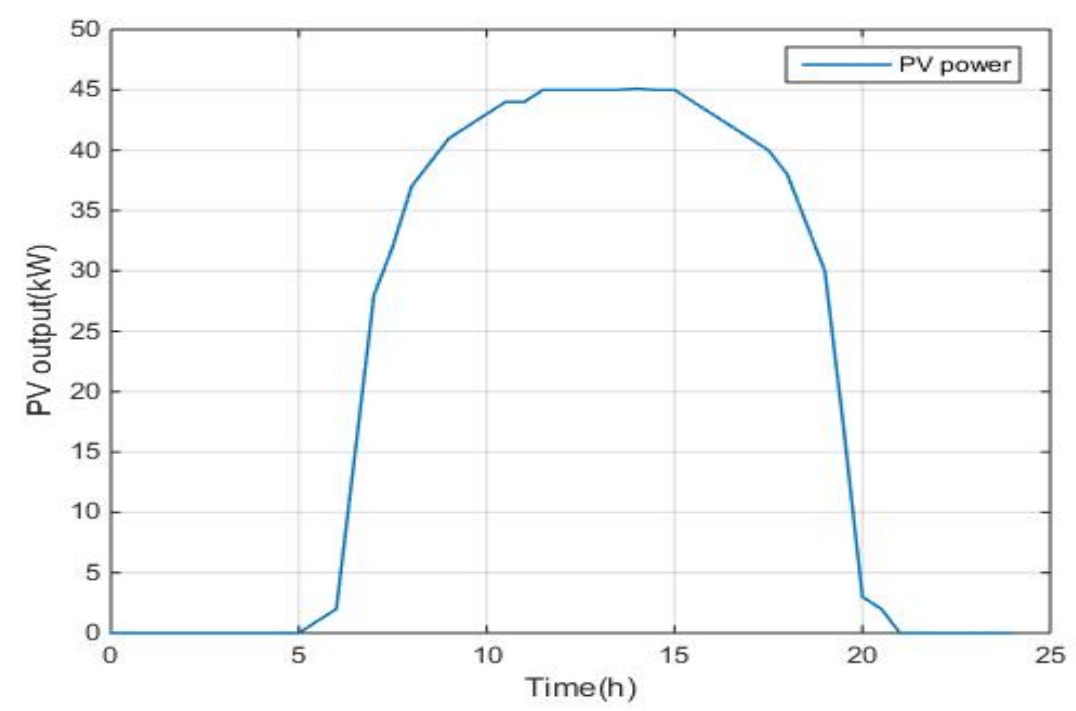

Fig. 4. PV Output Power

Table 1. Time of Use Price Structure

\begin{tabular}{lcl}
\hline & Period & Price $(\$ / \mathrm{kWh})$ \\
\hline Off-Peak & $19: 00-07: 00$ & 0.101 \\
& & \\
\hline Mid-Peak & $07: 00-11: 00$ & 0.141 \\
& $17: 00-19: 00$ & \\
\hline On-Peak & $11: 00-17: 00$ & 0.208 \\
\hline
\end{tabular}

\subsection{Case Study 1}

In this case, uncoordinated charging without the PV system or V2G is implemented. The EV will be plugged out from the charger after satisfying the charging request. However, the EV is assumed to park till its departure time. The day ahead operation cost and the energy coming from the electric network in a period of $24 \mathrm{~h}$ are displayed in Table 2 where the negative sign denotes the profit of the charging station. The charging profile of the charging station for one day is shown in Fig. 5. This profile shows that there is a high demand for the charging during the On-Peak and the Mid-Peak periods such as from 10:30 to 11:30 which increases the charging cost and might impact the grid by increasing the peak demand. Accordingly, the uncoordinated charging might have adverse effects on the electric network, increase the operating cost of the charging station which will be reflected on the price paid by the EVs owners.

\subsection{Case Study 2}

This case is the same as Case 1 but using PV panels. In this case, the charging profile of the charging station for one day is shown in Fig. 6. It is obvious that the EVs can be charged from the grid and/or the PV panels during the day. Thus, the EVs charging from the grid decreases compared to Case 1. If the power demand for EVs charging exceeds the PV generation, the remaining power is provided from the grid such as from 8:00 to 14:30. In contrast, from 16:00 to 17:00, the PV output power is greater than the EVs charging power so the surplus energy is injected to the grid. The high demand for the charging that occurs during the On-Peak and the 
Mid-Peak periods such as from 10:30 to 11:30 is supplied from both the electric network and the PV panels which might impact the grid by decreasing the peak demand compared to Case 1. When there is no PV generation, the EVs charge from the grid only and it occurs at OffPeak period such as from 3:00 to 5:30. Therefore, as displayed in Table 2, the day ahead operation cost is less than that of Case 1 which means that the profit of the charging station increases and the energy coming from the electric network in a period of $24 \mathrm{~h}$ is lower than Case 1.

\subsection{Case Study 3}

In this case, coordinated EV charging/discharging (using V2G) with PV panels is implemented. The day ahead operation cost and the energy provided from the electric network are displayed in Table 2. In addition, the charging/discharging profile of the station is displayed in Fig. 7. At 8:00, the PV output power is greater than the EVs charging power demand, so the surplus energy is injected to the grid. When the EVs charging demand exceeds the PV generation, the remaining EVs charging demand is provided from the grid such as from 11:30 to 15:00 or provided from EVs discharging such as at 11:00 and 15:30. From Fig. 7 , it is shown that most of EVs discharging occurs during the On-Peak period which helps reducing the operation cost and decreases the peak demand of the charging station. When there is no PV generation, the EVs charge from the grid only such as from 23:30 to 24:00 or charge from both the grid and EVs discharging such as at 22:00. Despite the charging station owner added participation bonus for encouraging EVs to contribute in the discharging program and also the energy provided from the grid in a period of $24 \mathrm{~h}$ is greater than Case 2 , the operation cost of the charging station has minimized which means that the profit of the charging station has increased compared to the previous cases.

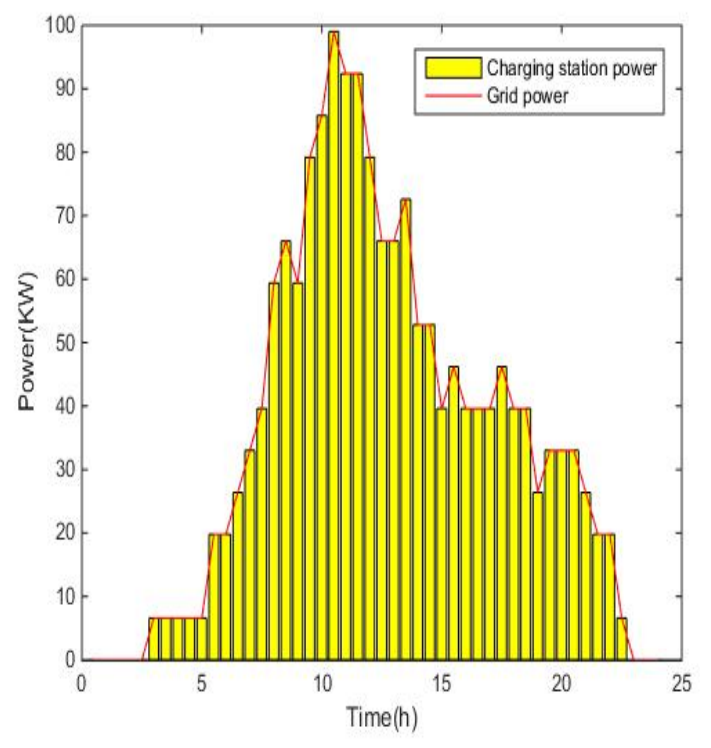

Fig. 5. Charging Station Profile for Case Study 1

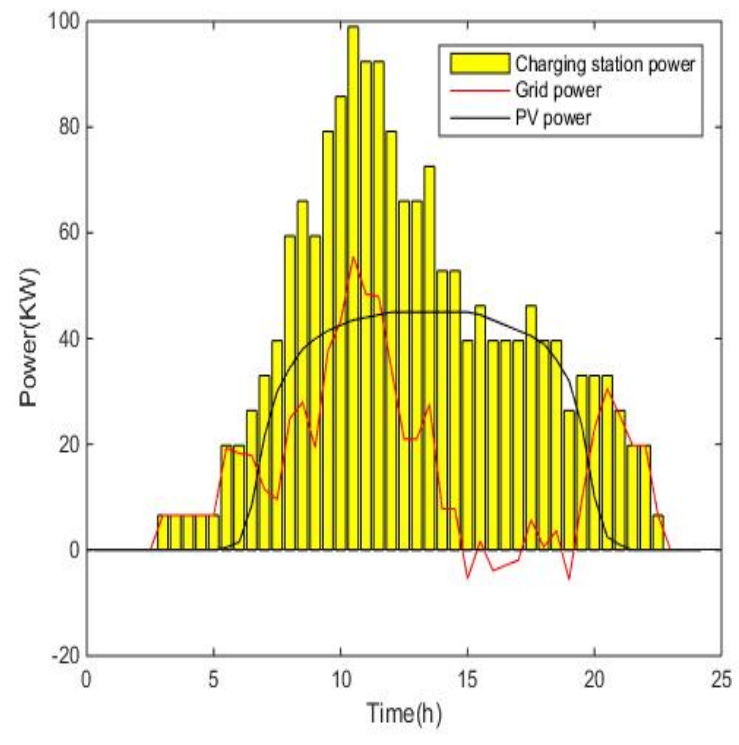

Fig. 6. Charging Station Profile for Case Study 2 


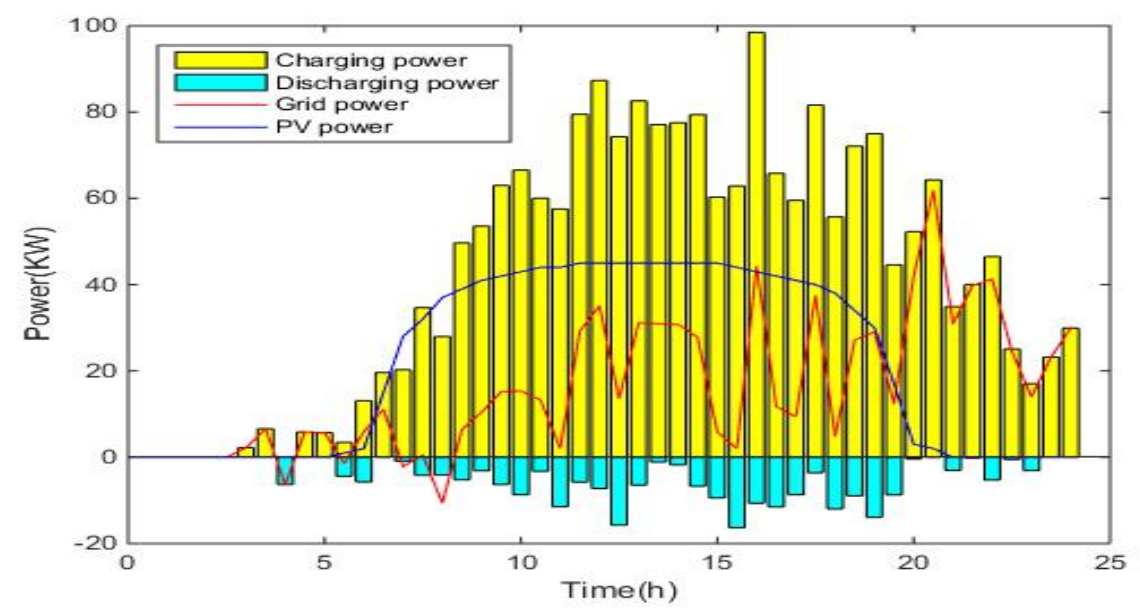

Fig. 7. Charging Station Profile for Case Study 3

Table 2. Results of The Three Cases

\begin{tabular}{|l|c|c|}
\hline & Operation cost (\$/day) & Energy from the grid $(\mathrm{kWh})$ \\
\hline Case 1 & -25.83 & 886.30 \\
\hline Case 2 & -117.63 & 340.15 \\
\hline Case 3 & -124.75 & 395.55 \\
\hline
\end{tabular}

\section{CONCLUSION}

In this paper, day-ahead charging/discharging scheduling of EVs in a charging station powered by roof-top PV panels has been studied. The PV panels are integrated in the charging station to help reducing the operating cost and harmful gas emissions. The study attempts to utilize each part of the proposed system efficiently and manage the energy trading based on TOU price. The main objective of the problem is to minimize the operation cost of the charging station using whale optimization algorithm. Several cases have been studied and the results show the ability of the proposed approach to increase the profit of the charging station and at the same time satisfy the EV users' requirements.

\section{REFERENCES:}

1. "Climate Watch." [online]

Available: https://www.climatewatchdata.org/ghg-emissions.

2. Mouli, G. R., Leendertse, M., Prasanth, V., Bauer, P., Silvester, S., Van de Geer, S., \& Zeman, M. (2016). Economic and CO2 emission benefits of a solar powered electric vehicle charging station for workplaces in The Netherlands. 2016 IEEE Transportation Electrification Conference and Expo (ITEC)

3. “Global EV Outlook 2019,” Int. Energy Agency, p.16, 2019.

4. Salama, H. S., Said, S. M., Vokony, I., \& Hartmann, B. (2019). Impact of different plug-in electric vehicle categories on distribution systems. 2019 7th International Istanbul Smart Grids and Cities Congress and Fair (ICSG).

5. Amini, M. H., Boroojeni, K. G., Cheng Jian Wang, Nejadpak, A., Iyengar, S., \& Karabasoglu, O. (2016). Effect of electric vehicle parking lots' charging demand as dispatchable loads on power systems loss. 2016 IEEE International Conference on Electro Information Technology (EIT)

6. Mukherjee, J. C., \& Gupta, A. (2015). A review of charge scheduling of electric vehicles in smart grid. IEEE Systems Journal, 9(4), 1541-1553. 
7. Ninkovic, T., Calasan, M., \& Mujovic, S. (2020). Coordination of electric vehicles charging in the distribution system. 2020 19th International Symposium INFOTEH-JAHORINA (INFOTEH).

8. Shi, R., Xu, L., \& Xue, Y. (2018). Research on coordinated charging strategy of electric vehicles based on PSO algorithm. 2018 Chinese Automation Congress (CAC)

9. Lan, T., Hu, J., Kang, Q., Si, C., Wang, L., \& Wu, Q. (2013). Optimal control of an electric vehicle's charging schedule under electricity markets. Neural Computing and Applications, 23(7-8), 1865-1872.

10. Ivanova, A., Fernandez, J. A., Crawford, C., \& Djilali, N. (2017). Coordinated charging of electric vehicles connected to a net-metered PV parking lot. 2017 IEEE PES Innovative Smart Grid Technologies Conference Europe (ISGT-Europe).

11. Jhala, K., Natarajan, B., Pahwa, A., \& Erickson, L. (2014). Coordinated electric vehicle charging solutions using renewable energy sources. 2014 IEEE Symposium on Computational Intelligence Applications in Smart Grid (CIASG).

12. Sarabi, S., Bouallaga, A., Davigny, A., Robyns, B., Courtecuisse, V., Riffonneau, Y., \& Regner, M. (2014). The feasibility of the ancillary services for vehicle-to-grid technology. 11 th International Conference on the European Energy Market (EEM14).

13. Erdinc, O., Mendes, T. D., \& Catalao, J. P. (2014). Impact of electric vehicle V2G operation and demand response strategies for smart households. 2014 IEEE PES T\&D Conference and Exposition.

14. Xing, H., Fu, M., Lin, Z., \& Mou, Y. (2016). Decentralized optimal scheduling for charging and discharging of plug-in electric vehicles in smart grids. IEEE Transactions on Power Systems, 31(5), 4118-4127.

15. "Level Up Your EV Charging Knowledge," ChargePoint. [Online]. Available: https://www.chargepoint.com/blog/level-your-ev-charging-knowledge/.

16. "Honda to Start Electric Vehicle Testing Program in Japan," wordlessTech, 09-Jun-2012. [Online]. Available: https://wordlesstech.com/honda-to-start-electric-vehicle-testing-programin-japan/.

17. Mirjalili, Seyedali \& Lewis, Andrew. (2016). The Whale Optimization Algorithm. Advances in Engineering Software, vol.95, pp. 51-67,2016.

18. Hydro Ottawa Limited, Hydro Ottawa. [Online]. Available:

19. https://hydroottawa.com/accounts-services/accounts/time-use. [Accessed: April 2020] 